\title{
Design and analysis of dual band integrated hexagonal shaped microstrip UWB antenna
}

\author{
Alaa Desher Farhood ${ }^{1}$, Maham Kamil Naji ${ }^{2}$, Suhad Hasan Rhaif ${ }^{3}$, Adnan Hussein Ali ${ }^{4}$ \\ ${ }^{1,4}$ Electronic Techniques Department, Technical instructors training institute, \\ Middle Technical University, Iraq \\ ${ }^{2}$ Electronic Techniques Department, Institute of Technology, Middle Technical University, Iraq \\ ${ }^{3}$ Electrical Techniques Department, Technical instructors training institute, Middle Technical University, Iraq
}

\begin{tabular}{l}
\hline Article Info \\
\hline Article history: \\
Received Oct 1, 2018 \\
Revised Dec 10, 2018 \\
Accepted Jan 25, 2019 \\
\hline Keywords: \\
Bluetooth \\
CLLR \\
Dual band \\
FEM \\
HFSS \\
Microstrip antenna \\
Resonant frequency \\
Return loss \\
VSWR \\
\hline
\end{tabular}

\begin{abstract}
In this paper, we proposed a hexagonal shaped microstrip ultra-wideband (UWB) antenna integrated with dual band applications. The antenna design consists of a hexagonal shape patch with two folded Capacitive Loaded Line Resonators (CLLRs) on the left edge of the patch antenna. This hexagonal structure is used to implement UWB applications (3.1-10.6 GHz). A rectangular ground, and two CLLR are also used on the bottom of antenna to obtain the extra dual resonant frequency at $2.4 \mathrm{GHz}$ and $9.1 \mathrm{GHz}$ for Bluetooth and radar applications respectively. The proposed design is implemented using FR4 epoxy substrate. The relative permittivity of the substrate is 4.4 . The overall size of designing antenna is $26 \times 30 \mathrm{~mm} 2$ with $1.6 \mathrm{~mm}$ as thickness and fed by standard feed line of $50 \Omega$ microstrip. The results obtained from the simulation indicate that the designed antenna attains a good bandwidth from $1.1 \mathrm{GHz}-10.69 \mathrm{GHz}$ with VSWR $<2$ and return loss $<-10 \mathrm{~dB}$. The proposed geometry is simulated by using the Ansoft HFSS simulator working on the principle of FEM and results are also analyzed.
\end{abstract}

Copyright $\odot 2019$ Institute of Advanced Engineering and Science. All rights reserved.

\section{Corresponding Author:}

Alaa Desher Farhood,

Technical Instructors Training Institute,

Middle Technical University,

Baghdad, Iraq.

Email: alaa.desher@gmail.com

\section{INTRODUCTION}

In 2002, the Federal Communications Commission (FCC) announces the frequency bandwidth of ultra wideband (UWB) system. The commercial bandwidth of UWB is $3.1-10.6 \mathrm{GHz}$. This is the very large frequency bandwidth in the communication system. Due to the very fast development in wireless communication system, a very large number of researchers have given their research interest in designing and implementation of various type of antenna for UWB applications. The UWB antenna has some special features such as low power consumption, high data rate, omni directional with maximum accuracy. The size of the antenna also becomes compact with minimum cost. For communication applications, the FCC provides - 41.3dBm/MHz as an effective isotropic spectral power density of the UWB bandwidth system [1,2].

In other hand, the designing part of the UWB antenna has some challenges like electromagnetic interference (EMI), compact antenna design with good result of radiation pattern and impedance matching properties over the entire frequency band from 3.1-10.6 GHz [3-4]. Due to wide spectrum bandwidth of UWB system, a lot of researcher puts their interest to enhance the research technology for UWB applications in different communication systems [5-10]. In UWB microstrip patch antenna, it consists of radiating patches on the upper side of antenna called dielectric substrate, whereas ground is designed on the back side of 
antenna. Microstrip antennas are compact in size, light weighted, and are easy to implement with low complexity. This antenna has several used in modern communication system such as satellite communication, mobile, missile system etc [11].

In previous years, to increase the performance and working bandwidth of the microstrip UWB antenna, a large number of research have been carried out on the shape of the microstrip UWB antenna such as I-shaped notch [12], U-shaped, CPW fed fractal patch antenna, diamond shaped monopole antenna [13], and similarly slotting techniques have also used like truncated corners, hexagonal, central patch, rectangular slot patch [14-17]. In addition, due to the increasing demands of modern communication system, it is necessary to integrate different frequency bands within the UWB applications. Therefore, it is a significant parameter to design UWB antenna which is integrated with different frequencies with small size, ease of manufacturing and can be used in different purpose.

For adding extra bands, different methods are proposed for implementation of these structures such as multiband performance is achieved by employing three L-shaped or elliptical-shaped strips in the ground plane of the antenna [18-19], circular etched with inverted L-shaped strip [20] provides UWB frequency integrated with three other L, C and X band applications. Similarly, other structure are alos used like inverted U-shaped strip, two extra bands are added to the UWB antenna [21]. In the above [18-19] and [21], the entire UWB frequency spectrum is not covered by the proposed design.

In this paper, a simple, compact UWB antenna is proposed integrated with dual band for Bluetooth and Radar applications. In the proposed design, it consists of a hexagonal patch antenna designed above the dielectric substrate. On the bottom side of the antenna, a rectangular ground is provided. From this structure, UWB band 3.1 - 10.6 GHz is obtained. In order to integrate the other two resonant frequencies for Bluetooth $(2.4-2.48 \mathrm{GHz})$ and Radar $(8-12 \mathrm{GHz})$, a pair of two inverted L-shaped Capacitive Loaded Line Resonators (CLLRs) are introduced at the left side with the rectangular ground plane side of the antenna [22-26]. With inverted L-shaped strip [20] provides UWB frequency integrated with three other L, C and X band applications. Similarly, other structure are also used like inverted U-shaped strip, two extra bands are added to the UWB antenna [21]. In the above [18-19] and [21], the entire UWB frequency spectrum is not covered by the proposed design.

\section{ANTENNA DESIGN}

In Figure 1, a general structure of designing antenna is shown. The antenna structures consist of a hexagonal shape with one rectangular feed structure on the top side of the antenna. On the back side of the antenna, a rectangular ground is designed which is connected with two inverted L-shaped capacitive loaded line resonator. The antenna is designed on an FR4 substrate with substrate dimension of $26 \times 30 \mathrm{~mm} 2$ and thickness $\mathrm{h}=1.6 \mathrm{~mm}$. The substrate has a relative permittivity of 4.4. By using the hexagonal shape design on the top surface of the substrate, it provides the UWB frequency band. To obtain the other desired two resonant frequencies such as $2.4 \mathrm{GHz}$ and $9.1 \mathrm{GHz}$, two additional strips as a CLLR are designed and connected to the rectangular ground. The dimension of rectangular ground is $13.15 \mathrm{~mm} \times 30 \mathrm{~mm}$ and the dimensions of first and second strips are $11.85 \mathrm{~mm} \times 0.5 \mathrm{~mm}$ and $(12.35 \mathrm{~mm}+1.5 \mathrm{~mm}+1.5 \mathrm{~mm})$ $\times 0.5 \mathrm{~mm}$ respectively.

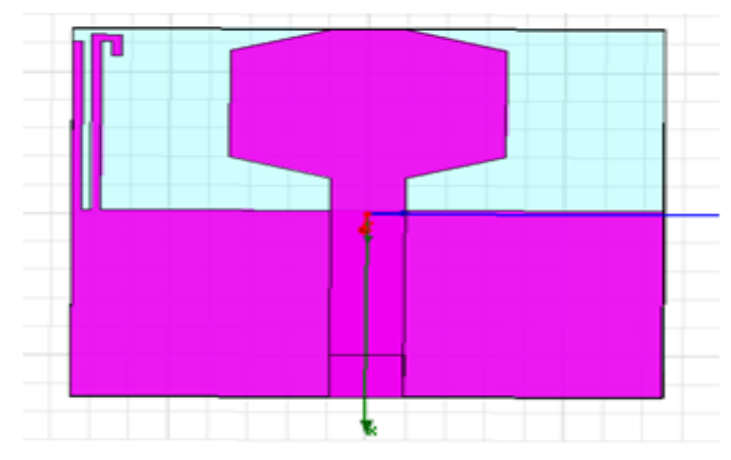

Figure 1. A general view of proposed antenna

In the proposed antenna, both the CLLRs are designed on the same side of antenna. The width of CLLR is $0.5 \mathrm{~mm}$ and the gap between the two resonator is also $0.5 \mathrm{~mm}$. 
To design the resonator, $\lambda_{g} / 4$ can be taken as length [22], where $\lambda_{g}$ is given by

$$
\begin{aligned}
& \lambda_{g}=\frac{c}{f \sqrt{\varepsilon_{e f f}}} \\
& \varepsilon_{e f f}=\left(\varepsilon_{r}+1\right) / 2
\end{aligned}
$$

From the above equation, $\lambda_{g}$ can be determined from the resonant frequency, velocity of light and permittivities. The design structure and dimensions of the antenna is given in Figure 2. The proposed antenna designing parameters i mention in Table 1.

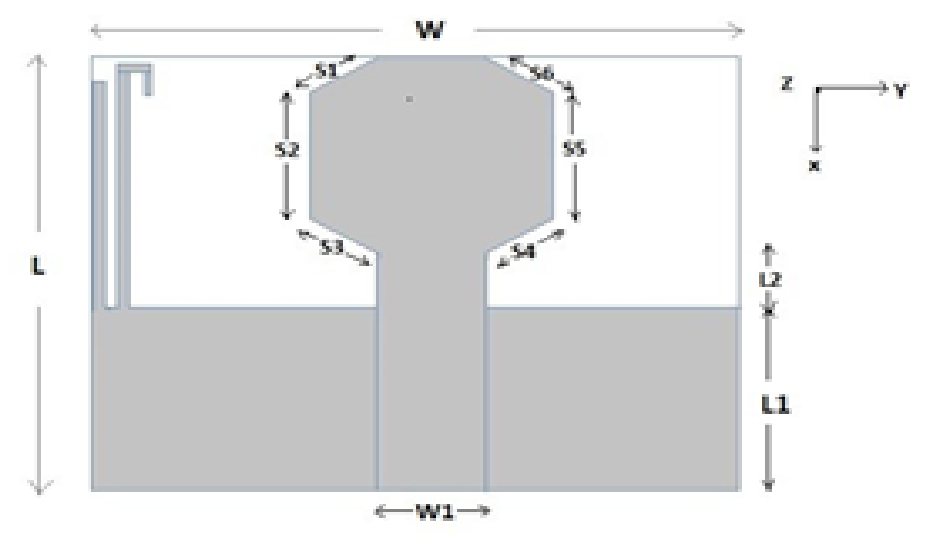

Figure 2. Geometry and dimensions of the proposed antenna

Table 1. Proposed Antenna Design Parameters

\begin{tabular}{cccc}
\hline Parameters & Value $(\mathrm{mm})$ & Parameters & Value $(\mathrm{mm})$ \\
\hline L & 26 & S2 & 7.5 \\
W & 30 & S3 & 5.32 \\
L1 & 13.15 & S4 & 5.32 \\
W1 & 3.8 & S5 & 7.5 \\
L2 & 2.35 & S6 & 5.32 \\
S1 & 5.32 & & \\
\hline
\end{tabular}

The antenna is fed by a microstrip feed line of 50-Ohm to enhance the impedance matching property of the antenna. Different configuration of antenna (a) Top view (b) Bottom view as shown in Figure 3 and Equivalent circuit model of proposed antenna as shown in Figure 4.

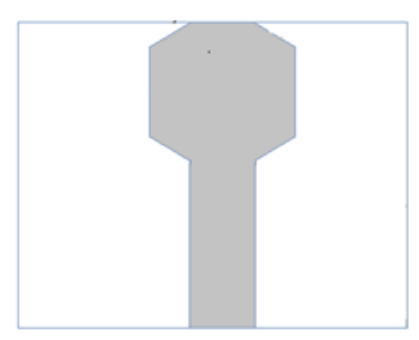

(a)

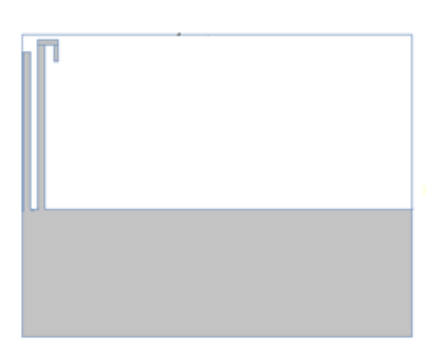

(b)

Figure 3. Different configuration of antenna (a) Top view (b) Bottom view 


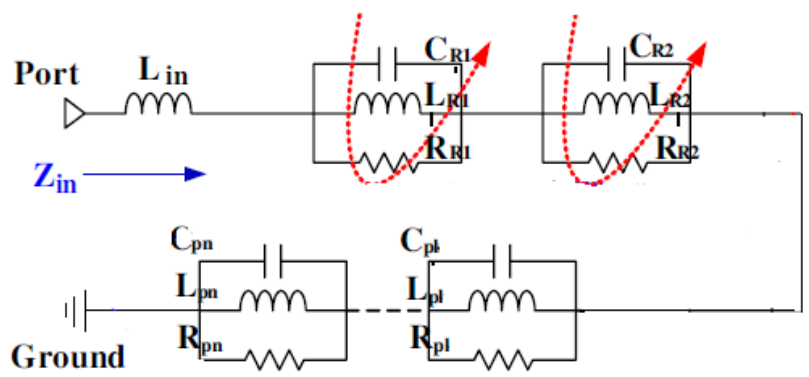

Figure 4. Equivalent circuit model of proposed antenna

\section{SIMULATION RESULT AND ANALYSIS}

The design and simulation of the proposed antenna are done with the help of Ansoft High Frequency Structure Simulator (HFSS) simulation tool. Ansoft HFSS is an electromagnetic simulator, which is based on finite element method (FEM) technique [27]. The simulated results of the projected antenna are discussed below. These results clearly indicate that the proposed antenna covers UWB frequency band from (3.1-10.6) $\mathrm{GHz}$ along with the integration of dual resonant frequencies centered at $2.4 \mathrm{GHz}$ and $9.1 \mathrm{GHz}$. From Figure 5, it is clear that the simulated antenna has better return loss of - $34 \mathrm{~dB}$ and $-23.22 \mathrm{~dB}$ at $.4 \mathrm{GHz}$ and $9.1 \mathrm{GHz}$ respectively $(\mathrm{S} 11<-10 \mathrm{~dB})$.

Figure 6 shows the simulated VSWR result. It is also under the desired condtions (VSWR $\leq 2$ ) for UWB range as well as dual frequencies at $2.4 \mathrm{GHz}$ and $9.1 \mathrm{GHz}$ respectively. Figure 7 show Far-field radiation pattern (a) Radiation pattern at $2.4 \mathrm{GHz}$ (b) Radiation pattern at $9.1 \mathrm{GHz}$ and Figure 8 show Field plot of the proposed antenna E- field and (b) H-field

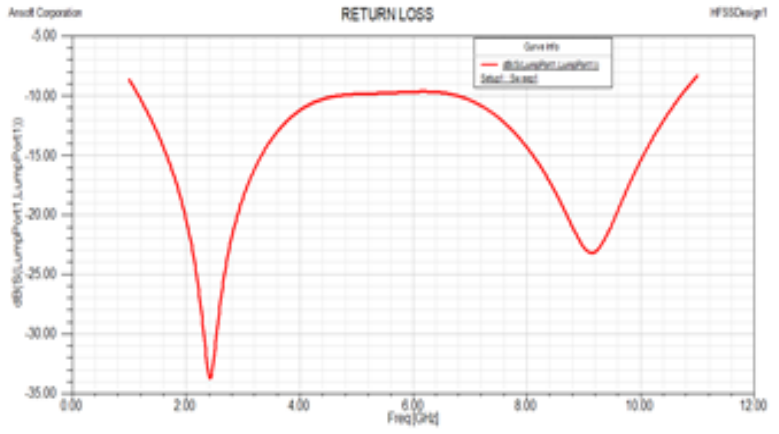

Figure 5. Simulated Return loss (S11) Result

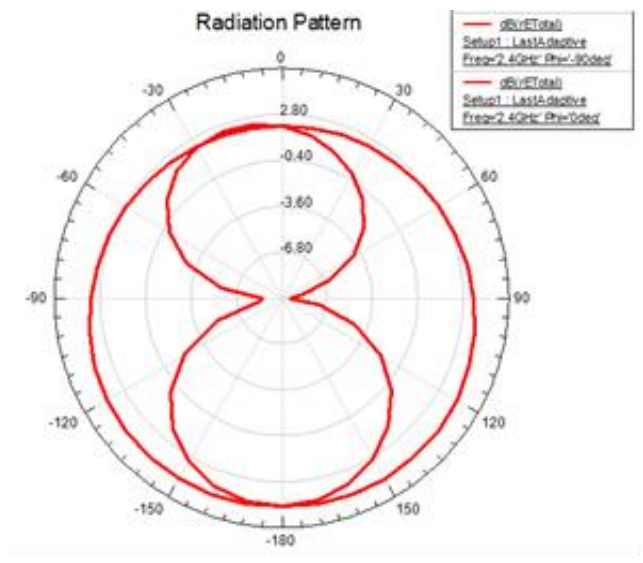

(a)

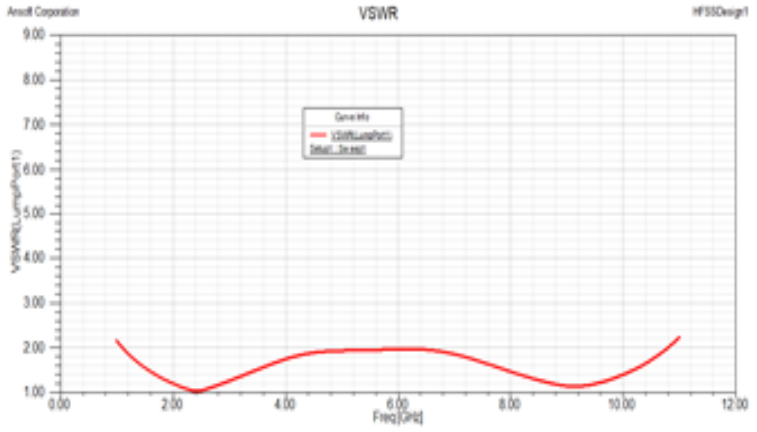

Figure 6. Simulated VSWR Result

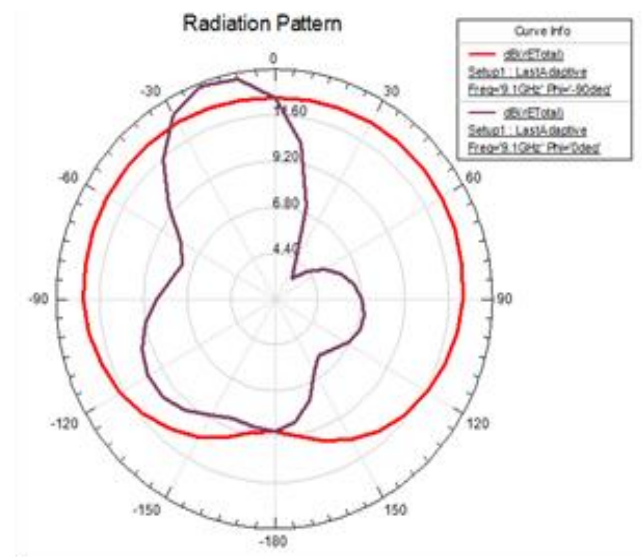

(b)

Figure7. Far-field radiation pattern (a) Radiation pattern at $2.4 \mathrm{GHz}$ (b) Radiation pattern at $9.1 \mathrm{GHz}$ 


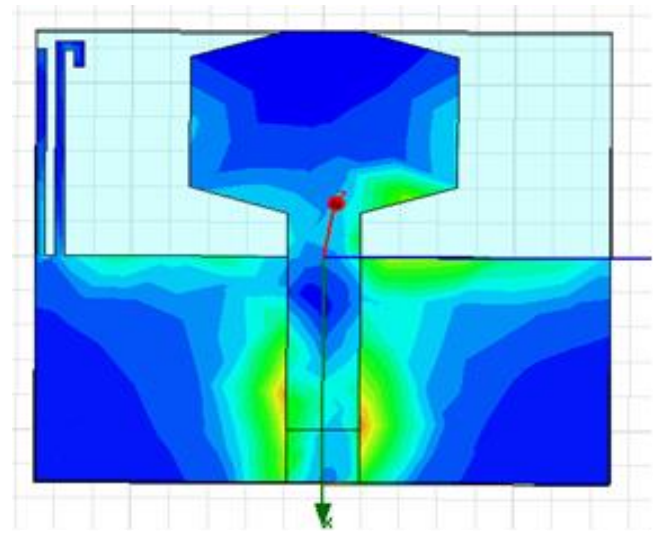

Figure 8. Field plot of the proposed antenna E- field and (b) H-field

\section{CONCLUSION}

A compact hexagonal shaped UWB antenna has designed and analysed with significant results. This antenna has also achieved dual band integrated applications. The hexagonal shaped conducting patch is used to achieve the UWB band (3.1-10.6 GHZ). By adding two CLLRs on the rectangular ground, two extra bands can be obtained. From the simulated results, the antenna provides stable and omni-directions radiation patterns and stable gain throughout the UWB band along with two other bands. The proposed antenna has excellent return loss, VSWR and gain for UWB frequency range (3.1-10.6 GHz) along with Bluetooth and radar applications at $2.4 \mathrm{GHz}$ and $9.1 \mathrm{GHz}$ respectively. The designed antenna has an operating bandwidth of 1.1-10.69 GHz $(9.59 \mathrm{GHz})$ and this makes the proposed antenna is a suitable candidate for UWB applications and systems integrated with other two dual band applications.

\section{REFERENCES}

[1] First report and order,(2002) " Revision of Part 15 of the commission's rule regarding ultra wideband transmission system FCC02-48”, Federal Communications Commission.

[2] Mishra, S. K., R. K. Gupta, A. Vaidya, and J. Mukherjee, "Printed Fork Shaped Dual Band Monopole Antenna For Bluetooth And Uwb Applica tions With 5.5GHz WLAN Band Notchedchar-Acteristics," Progress In Electromagnetics Research C, Vol. 22, 195-210, 2011.

[3] Lizzi, L., G. Oliveri, and A. Massa, "A time-domain approachvto the synthesis of UWB antenna systems," Progress In Electromagnetics Research, Vol. 122, 557-575, 2012.

[4] S. M. Shah, K. Hamdan, Z. Z. Abidin, F. C. Seman, S. A. Hamzah, N. Katiran, F. Zubir, "Frequency tuning varactor-loaded reconfigurable antenna for m-WiMAX and WLAN applications", Indonesian Journal of Electrical Engineering and Computer Science(IJEECS), Vol 13, No 2: February 2019.

[5] Agrawall, N., G. Kumar, and K. Ray, "Wide-band planar monopole antennas," IEEE Trans. Antennas Propag., Vol. 46, 294-295, 1998.

[6] Gopikrishna, M., D. D. Krishna, A. R. Chandran, and C. K. Aanandan, "Square monopole antenna for ultra wide band communication applications," Journal of Electromagnetic Waves and Applications, Vol. 21, No. 11, 15251537, 2007.

[7] Ching, W. L., W. H. Lo, R. H. Yan, and S. J. Chung, "Planar binomial curved monopole antennas for UWB communication," IEEE Trans. Antennas Propag., Vol. 55, 2622-2624, 2007.

[8] Yin, X.-C., C.-L. Ruan, C.-Y. Ding, and J.-H. Chu, "A planar U type monopole antenna for UWB applications," Progress In Electromagnetics Research Letters, Vol. 2, 1-10, 2008.

[9] Evans, J. A. and M. J. Ammann, "Planar monopole design considerations based on TLM estimation of current density," Microwave Opt. Technol. Lett., Vol. 36, 40-42, 2003.

[10] Mishra, S. K., R. K. Gupta, and J. Mukherjee, "Parallel metal plated tuning fork shaped omnidirectional monopole antenna for UWB application," Microwave Opt. Technol. Lett., Vol. 53, No. 3, 601-604, Mar. 2011.

[11] Balanis C. A, "Microstrip Antennas", Antenna Theory, Analysis and Design, Third Edition, John Wiley \& Sons, pp-811-876, 2010.

[12] M. Abdollahvand, G. Dadashzadeh, and D. Mostafa, "Compact dual band-notched Printed monopole antenna for UWB Applications," IEEE Antennas and Wireless Propagation Letters, vol. 9, pp. 1148-1151, 2010.

[13] Sarthak Singhal, Tushar Goel and Amit Kumar Singh, "Novel Diamond Shaped UWB Monopole Antenna," 2013 Annual IEEE India Conference (INDICON), pp. 1-6, Mumbai, 13-15 Dec. 2013. 
[14] S. Z. N. Zool Ambia, M. H. Jamaluddin, M.R. Kamarudin, J. Nasir, R.R. Selvaraju, " Evolution of H-shaped dielectric resonator antenna for 5G applications", Indonesian Journal of Electrical Engineering and Computer Science(IJEECS), Vol 13, No 2: February 2019.

[15] Mohammad Reza Ghaderi, and Farzad Mohajeri, "A Compact Hexagonal Wide-Slot Antenna With Microstrip-Fed Monopole for UWB Application”, IEEE Antennas And Wireless Propagation Letters, Vol. 10, 2011.

[16] Y. Sung, "Bandwidth Enhancement of a Microstrip Line-Fed Printed Wide-Slot Antenna With a Parasitic Center Patch", IEEE Transactions On Antennas And Propagation, Vol. 60, pp. 4, April 2012.

[17] Ritu Sharma and Dharti Raj Shah "Design A Dual Band Rectangular Slot Microstrip Patch Antenna for Bluetooth and WLAN Applications Using CLLR Technique" in International Journal of Advanced Research in Electronics and Communication Engineering (IJARECE), 2034-2038, Volume 5, Issue 7, July 2016, ISSN: 2278 - 909X.

[18] M. M. SamadiTaheri, H. R. Hassani, and S. M. "Ali Nezhad, "UWB Printed Slot Antenna With Bluetooth and Dual Notch Bands” IEEE Antennas Wireless Propag.Lett., vol.10,pp.255-258, 2011.

[19] M. Rahanandeh, A. S. Noor Amin, M. Hosseinzadeh, P. Rezai, and M. S. Rostami "A Compact Elliptical Slot Antenna for Covering Bluetooth/WiMAX/WLAN/ITU”, IEEE Antennas Wireless Propag.Lett., vol.11, pp.857860, 2012.

[20] Mukesh Kumar, Ritu Sharma and Dharti Raj Shah "A Novel Design And Analysis of Circularly Etched Uwb Antenna For L, C And X-Band Applications" in International Research Journal of Engineering and Technology (IRJET), 96-100, Volume 3, Issue 11, November 2016, ISSN: 2395 -0056.

[21] M. Bod, H. R. Hassani, M. M. Samadi Taheri, "Compact UWB Printed Slot Antenna With Extra Bluetooth, GSM, and GPS Bands,” Electronics Lett., vol. 11, pp.531-534, Mar. 2012.

[22] Ali Khalid Jassim, Raad H. Thaher, "Enhancement gain of broadband elliptical microstrip patch array antenna with mutual coupling for wireless communication", Indonesian Journal of Electrical Engineering and Computer Science(IJEECS), Vol 13, No 1: January 2019.

[23] Yildirim, B. S., B. A. Cetiner, G. Roquetra, and L. Jofre, "Integrated bluetooth and UWB antenna," IEEE Antennas Wireless Propag. Lett., Vol. 8, 149-152, 2009.

[24] Mishra, S. K., R. K. Gupta, A. Vaidya, and J. Mukherjee, “A compact dual-band fork-shaped monopole antenna for Bluetooth and UWB applications," IEEE Antennas Wireless Propag. Lett., Vol. 10, 627-630, 2011.

[25] S. M. Shah, K. Hamdan, Z. Z. Abidin, S. A. Hamzah, N. Katiran, F. Zubir, "Frequency tuning varactor-loaded reconfigurable antenna for m-WiMAX and WLAN applications", Indonesian Journal of Electrical Engineering and Computer Science(IJEECS), Vol 13, No 2: February 2019.

[26] Rahanandeh, M., A. S. Noor Amin, M. Hosseinzadeh, P. Rezai, and M. S. Rostami, "A compact elliptical slot antenna for covering bluetooth/WiMAX/WLAN/ITU," IEEE Antennas Wireless Propag. Lett., Vol. 11, 85-860, 2012.

[27] Ansoft Corporation - HFSS - www.ansoft.com 